\title{
The Possible Role of TLR2 in Chronic Hepatitis B Patients with Precore Mutation
}

\author{
Malihe Moradzadeh,, ${ }^{1}$ Sirous Tayebi, ${ }^{2}$ Hossein Poustchi, ${ }^{2}$ Kourosh Sayehmiri, ${ }^{3}$ \\ Parisa Shahnazari, ${ }^{4}$ Elnaz Naderi, ${ }^{1}$ Ghodratollah Montazeri, ${ }^{2}$ and Ashraf Mohamadkhani ${ }^{2}$ \\ ${ }^{1}$ Department of Modern Sciences and Technologies, School of Medicine, Mashhad University of Medical Sciences, Mashhad, Iran \\ ${ }^{2}$ Liver and Pancreatobiliary Diseases Research Center, Digestive Diseases Research Institute, Tehran University of Medical Sciences, \\ Tehran, Iran \\ ${ }^{3}$ Psychosocial Injuries Research Centre, Ilam University of Medical Sciences, Ilam, Iran \\ ${ }^{4}$ Monoclonal Antibody Research Centre, Avicenna Research Institute, ACECR, Tehran, Iran
}

Correspondence should be addressed to Ashraf Mohamadkhani; mohamadkhani.ashraf@gmail.com

Received 29 April 2013; Accepted 26 August 2013

Academic Editor: Stefan Pöhlmann

Copyright (C) 2013 Malihe Moradzadeh et al. This is an open access article distributed under the Creative Commons Attribution License, which permits unrestricted use, distribution, and reproduction in any medium, provided the original work is properly cited.

\begin{abstract}
Recognition mechanisms of innate immune response help to improve immunotherapeutic strategies in HBeAg-negative chronic hepatitis B (CHB). Toll-like receptor 2 (TLR2) is an important component of innate immunity. In this study, the frequency of precore mutations of the hepatitis B virus (HBV) and serum TLR2 were evaluated in CHB patients. Fifty-one patients with chronic hepatitis $\mathrm{B}$, negative for HBeAg and detectable HBV DNA, were examined for the presence of mutations in pre-core region of HBV genome by direct sequencing. Serum TLR2 was measured by enzyme-linked immunosorbent assay. Interactions of truncated HBeAg and TLR2 proteins were evaluated with molecular docking software. The G1896A pre-core mutation were detected in 29 (57\%) which was significantly associated with higher concentration of serum TLR2 in comparison with patients without this mutation (4.8 \pm 2.9 versus $3.4 \pm 2.2 \mathrm{ng} / \mathrm{mL}, P=0.03)$. There was also a significant correlation between serum ALT and TLR-2 $(r=0.46 ; P=0.01)$. Docking results illustrated residues within the $\mathrm{N}$-terminus of truncated HBeAg and TLR2, which might facilitate the interaction of these proteins. These findings showed the dominance of G1896A pre-core mutation of HBV variants in this community which was correlated with serum TLR2. Moreover TLR2 is critical for induction of inflammatory cytokines and therefore ALT elevation.
\end{abstract}

\section{Introduction}

Hepatitis B virus (HBV) infection is an important cause of chronic hepatitis, cirrhosis, and hepatocellular carcinoma (HCC) [1]. The transmission of HBV from infected mothers to neonates causes persistent infection [2]. Chronic infection of HBV is a global health problem. However, the prevalence and genotype distribution of HBV are different among the geographical areas [3]. The majority of chronic hepatitis $\mathrm{B}$ patients lose $\mathrm{HBe}$ antigen (HBeAg) and develop anti-HBe antibody, which is generally associated with a decrease in serum HBV DNA levels and a gradual accumulation of precore or core promoter mutations [4]. HBeAg-negative chronic hepatitis $\mathrm{B}$ is the predominant type of $\mathrm{CHB}$ in Mediterranean inhabitants [3]. Two types of precore and core promoter HBV mutations that reduce $\mathrm{HBeAg}$ formation are more frequent in regions where patients are predominantly infected with HBV genotype $\mathrm{D}[4,5]$. Infection with wild-type strains of HBV often induces mild symptoms and responds well to interferon alpha therapy, but patients infected with precore mutant variants may show clinical evidence of elevated or fluctuating ALT and HBV DNA [6]. The reason that precore negative mutants become predominant in some patients during chronic hepatitis B infection is not clear. However, the host immune system has a functional role in the selection of precore mutant strains of $\mathrm{HBV}$, and their appearance might reflect immunological control of infection $[7,8]$.

Infected hepatocytes are eliminated by vigorous CD4+ and CD8+ T-cell responses, and those who have insufficient cellular immune response will persist chronically infected [9]. 
The impact of innate immunity in liver damage also has been identified in several studies $[10,11]$. Toll-like receptors (TLRs) describe a group of pattern recognition receptors (PRRs) playing critical roles in the host innate immune response [12]. These proteins are evolutionarily conserved from Drosophila to humans and important in controlling the activation of the adaptive immune response [13]. Various TLRs exhibit different patterns of expression [14]. Overactivation of TLRs plays a prominent role in the pathogenesis of a variety of acute and chronic inflammatory conditions [13]. A previous study reports that the $\mathrm{HBeAg}$ downregulates antiviral defenses of the host [15] and, in the absence of HBeAg, HBV replication is associated with upregulation of the TLR2 pathway, resulting in increased TNF- $\alpha$ production [16-19]. A wide range of microbial and viral components as well as several endogenous TLR ligands are recognized by TLR2 [14]. This receptor is expressed in peripheral blood leukocytes, mainly in monocytes, in lymph nodes, bone marrow, and spleen [20]. TLR2 is also released by normal monocytes and is present in serum and other biological fluids which mostly contain the TLR2 extracellular domain [20, 21].

The importance of diverse TLRs for the "in vivo" replication and pathogenesis of HBV have been evidenced in several reports $[16,17]$. However, there are no reports of serum TLR2 in HBeAg negative chronic hepatitis B. In this study, the association of serum TLR2 with clinical findings in chronic hepatitis B patients especially in patients with G1896A stop codon mutation has been investigated.

\section{Patients and Methods}

2.1. Patients. A total of 51 chronic $\mathrm{HBeAg}$ negative patients with detectable HBV DNA and a range of normal to elevated ALT were evaluated during a period of 12 months. They perinatally acquired chronic infection as they had a clear history of familial HBV infection, without coinfection of human immunodeficiency virus (HIV), autoimmune hepatitis, and other hepatitis viruses. Blood samples were taken at the initial assessment before liver biopsy. Serum samples were stored at $-70^{\circ} \mathrm{C}$. No patient received anti-HBV therapy prior to liver biopsy. The protocol for the study was approved by the ethics committee of Shariati Hospital, Tehran, University of medical science.

2.2. Clinical Evaluation and $H B V-D N A$ Quantification. The presence of $\mathrm{HBsAg}, \mathrm{HBeAg}$, anti-HBeAg, anti-HCV, antiHDV, and anti-HIV were determined with commercial assay kit EIA, Dia.Pro diagnostic, Italy. Serum TLR2 was measured by toll-like Receptor2 ELISA Kit (Uscn Life Science, Wuhan, China) according to the manufacturer's specifications. Sensitivity of the ELISA for TLR2 was $0.312-20 \mathrm{ng} / \mathrm{mL}$.

HBV DNA was extracted from $200 \mu \mathrm{L}$ of serum using QIAamp DNA Blood Mini Kit (QIAGEN, USA), eluted in $50 \mu \mathrm{L}$ of elution buffer, and then measured in the Light-Cycler (Roche) by RealARTTM HBV LC PCR (QIAGEN, Hilden, Germany) according to the manufacturer's instructions. This assay had a linear range of $10^{2}-10^{9}$ copies $/ \mathrm{mL}$. Liver biopsies from all patients were assessed for the grade of histological activity and stage of fibrosis using the modified histological activity index (HAI) scoring system [22].

2.3. Precore G1896A Mutation Detection and Direct Sequencing. The precore region was analyzed by hemi-nested PCR according to Gan et al. [23]. The sense primer PC5 $5^{\prime}$-TCG CAT GGA GAC CAC CGT GA-3' (nt. 204-223) and the antisense primer PC2 $5^{\prime}$-GGC AAA AAC GAG AGT AAC TC$3^{\prime}$ (nt. 540-559) were performed as first round primers. An additional hemi-nested round of amplification was achieved using $2 \mu \mathrm{L}$ of the first round product as template and the antisense primer $5275^{\prime}$-GTA ACT CCA CAG WAG CTC C-3' (nt. 528-546). The numbering organization for primer nucleotides was in accordance to the genome sequence HPBADR1CG [23]. The PCR products were purified using PCR purification kit from MO BIO Laboratories Inc. (Carlsbad, CA, USA) based on the manufacturer's instructions and eluted in $100 \mu \mathrm{L}$ of elution buffer. The sequencing of PCR products was accomplished by the Big Dye Terminator Cycle sequencing Ready Reaction Kit Version 3.1 (Applied Biosystems, Foster City, CA, USA).

2.4. Statistical Analysis. Normality of data was assessed using One Sample Kolmogorov-Smirnov Test. Correlations between variables were analyzed using Pearson correlation coefficient $(r)$. The independent samples $t$-test is used to compare the means \pm standard deviation (SD) of data. The Mann-Whitney $U$ test was utilized to test equality of TLR2 and ALT between patients with G1896A precore mutation and patients without mutation. A $P$ value $<0.05$ was deemed statistically significant.

2.5. HBeAg and TLR2 Interaction Analysis. In order to identify the strongly associated functional of $\mathrm{HBeAg}$, the proteinprotein interaction solutions were mapped between $\mathrm{HBeAg}$ and TLR2. The sequence of truncated HBeAg amino acid, created as a result of a stop codon at position 28 of $\mathrm{HBeAg}$ and genomic mutation at base 1898 of HBV, was extracted from UniProt (P0C6H9). The tertiary structure of truncated HBeAg was built by Pepstr [24]. The Pepstr server predicts the tertiary structure of small peptides with sequence length varying of 7 to 25 (residues http://www.imtech.res.in/raghava/pepstr/). The X-ray crystal structure of the TLR2 (2Z80A) was retrieved from PDB (Protein Data Bank) [25]. The PatchDock web server and a refinement by FireDock evaluate the molecular docking of both proteins $[26,27]$.

\section{Results}

3.1. Demographic and Clinical Characteristics of the Patients. Demographic characteristics and frequency of the G1896A precore mutation along with the clinical and biochemical profiles of study subjects are summarized in Table 1. There were a total of 51 patients (mean age $37 \pm 10 \mathrm{yr}$ ) including 16 females and 35 males. The quantification of HBV DNA was reported in $\log$ copies $/ \mathrm{mL}$ with a mean value of $3.46 \pm 1.06$ and 29 (57\%) patients that showed the G1896A precore mutation. Total score of necroinflammatory grade and fibrosis stage 
TABLE 1: Clinical and pathological data of 51 chronic hepatitis B patients with and without precore mutation G1896A.

\begin{tabular}{lccc}
\hline Clinical factor & All subjects $(n=51)$ & $\begin{array}{c}\text { Patients with } \\
\text { wild-type variant } \\
(n=22)\end{array}$ & $\begin{array}{c}\text { Patients with G1896A } \\
\text { mutation }(n=29)\end{array}$ \\
\hline Age (years) & $37 \pm 10$ & $36 \pm 9$ & $38 \pm 11$ \\
log HBV DNA (copies/mL) & $3.46 \pm 1.06$ & $3.54 \pm 1.03$ & $3.41 \pm 1.10$ \\
ALT (IU/L) & $57 \pm 56$ & $41 \pm 27$ & $68 \pm 67$ \\
TLR2 (ng/mL) & $4.2 \pm 2.7$ & $3.4 \pm 2.2$ & 0.4 \\
Histological activity index (HAI) score & $4.8 \pm 2.3$ & $4.2 \pm 1.7$ & 0.5 \\
\hline
\end{tabular}

${ }^{*}$ Mean $\pm \mathrm{SD},{ }^{* *} P$ value computed using the Mann-Whitney test.

were measured based on the modified HAI system and serum ALT were $4.8 \pm 2.3$ and $57 \pm 56 \mathrm{IU} / \mathrm{I}$, respectively. The mean concentration of serum TLR2 was $4.2 \pm 2.7 \mathrm{ng} / \mathrm{mL}$.

\subsection{Clinical Significance of G1896A Precore Mutation and} Serum TLR2. The concentration of serum TLR2 was higher in G1896A precore mutants than wild-type infected patients $(4.8 \pm 2.9$ versus $3.4 \pm 2.2 \mathrm{ng} / \mathrm{mL}, P=0.032)$ (Table 1$)$. There was no significant relationship between G1896A mutation variants with neither age nor sex. Patients infected with the wild-type HBV revealed similar mean of viral load compared to G1896A precore mutant patients $(3.54 \pm 1.02$ versus $3.41 \pm$ $1.1 \log$ copies $/ \mathrm{mL}$ ). More likely, patients who harbored the precore mutant strains had higher levels of serum ALT and HIA score compared to those patients infected with wild-type strain of HBV, however it was not statistically significant (68 67 versus $41 \pm 27 \mathrm{IU} / \mathrm{I}$ and $5.3 \pm 2.6$ versus $4.2 \pm 1.7$ ) (Table 1 ). Serum TLR2 and ALT had significant correlation $(r=0.46$; $P=0.01)$ which was more pronounced in patients with G1896A mutation $(r=0.48 ; P=0.008)$ (Figure 1). Furthermore, there was statistically significant association between the log HBV DNA with serum ALT and with HIA score $(r=$ $0.36 ; P=0.09$ and $r=0.3 ; P=0.03$ ). Serum ALT and HBV DNA did not show significant relationship to age, sex, and total grade of histological activity and stage of fibrosis.

3.3. TLR2 and Truncated HBeAg Interaction. In this experiment, the protein-protein docking of $\mathrm{HBeAg}$ and TLR2 were studied by PatchDock bioinformatic docking tool. Then, high-throughput refinement of docking was selected by FireDock (Figure 2). Protein-protein docking and interaction simulations disclosed hydrogen and ionic bonds. The amino acid residues Cys14, Pro15, Thr16, Val17 and Gln18 from HBVD-truncated HBeAg bonded to Asp58, Leu59, Ser60, Asn61, Asn62 and Arg63 of TLR2, respectively.

\section{Discussion}

The dynamic state of chronic HBV infection is a result of interactions between the virus itself and the host immune response [3]. Accordingly, different phases in the natural course of HBV infection are observed. Patients in immune tolerant phase usually have high viral load and normal levels of serum ALT. However, during the immune clearance phase, patients have moderate levels of HBV replication and elevated

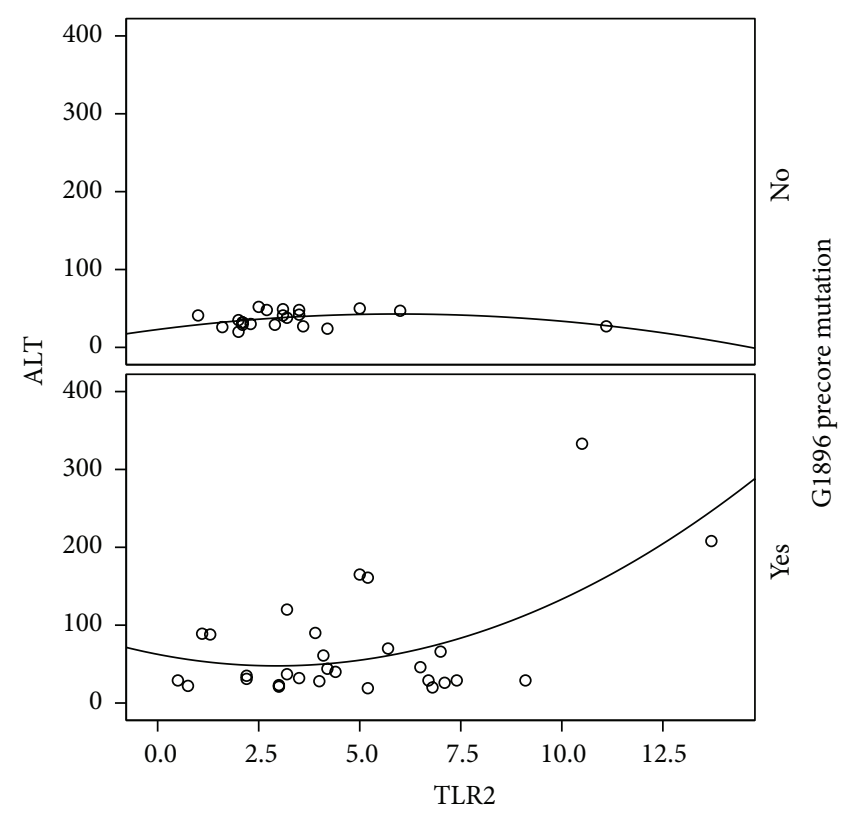

No $R^{2}$ quadratic $=0.159$

Yes $R^{2}$ quadratic $=0.33$

FIGURE 1: Estimating regression quadratic equation indicates that ALT sharply rises with increasing TLR2.

level of ALT $[3,28]$. The HBeAg has been proposed as a viral approach to induce immunotolerance. The precore and basic core promoter (BCP) genetic variations of $\mathrm{HBV}$ lead to $\mathrm{HBeAg}$ loss and anti-HBe seroconversion $[4,29]$. Principally, the stop codon mutation at base 1896 creates the truncated precore peptide that might represents an adaptation to immune pressure [30]. The function of innate immune response as the first line of defense against virus infection as well as its cooperation with adaptive immunity may induce the development of precore mutant variants of HBV [11, 31, 32]. Therefore, the clinical significance of these mutations appears to be linked to the function of host immune system.

The result of this study revealed the presence of HBV variants with precore mutations in $57 \%$ of anti-HBe-positive patients that explained the lack of $\mathrm{HBeAg}$ synthesis. Patients with precore mutants had higher concentrations of TLR2 compared to patients infected with wild-type HBV. Furthermore, increasing TLR2 is associated with serum ALT concentration in G1896A precore mutant patients. The increase of 


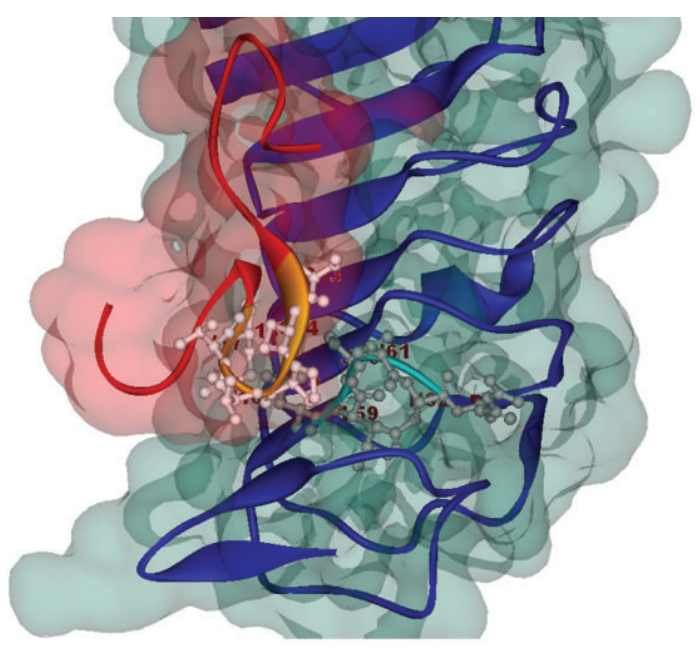

(a)

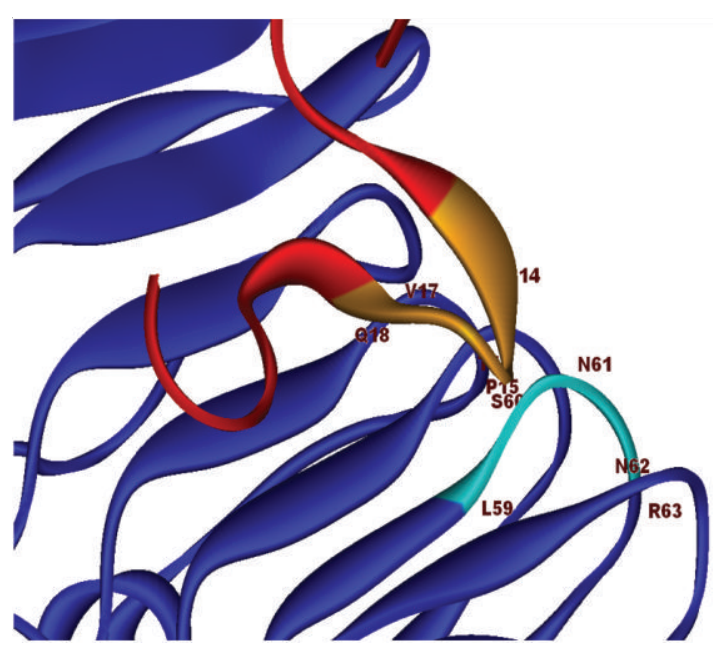

(b)

FIgURE 2: The docking result of HBeAg and TLR2. (a) The interaction of HBeAg with the accessible area of TLR2. (b) Docking of the a helices in the major groove of TLR2 with HBeAg as the ribbon form. The amino acids residues Cys14, Pro15, Thr16, Val17, and Gln18 of precore protein (HBeAg) colored in yellow bonding to Leu59, Ser60, Asn61, Asn62 and Arg63 of TLR2 that appeared in light blue.

serum ALT could reflect the hepatitis activity and the host immune response against $\mathrm{HBV}$ that induces apoptosis and necrosis [3]. These findings are consistent with a previous study reporting the association of $\mathrm{HBV}$ replication and activation of TLR2 in precore mutant patients [17]. The members of TLRs family play an essential role in the innate immune recognition $[12,16]$, are upregulated in response to microbial components $[33,34]$, and are critical for the development of effective immunity [14]. A downregulation of TLR2 receptor in peripheral blood monocytes of chronic patients infected with $\mathrm{HBeAg}$ positive variants has been shown previously [17]. Visvanathan et al. reported that wildtype (HBeAg-positive) and the precore stop codon (HBeAgnegative) $\mathrm{HBV}$ variants had different effects on TNF- $\alpha$ production. Moreover, they showed that the expression of TLR2 on hepatocytes, Kupffer cells, and peripheral monocytes were significantly increased in HBeAg-negative chronic hepatitis B [17]. Lian et al. also found that the expression of TLR2 was significantly upregulated in patients with liver cirrhosis and chronic hepatitis B patients [9]. Interestingly, the therapeutic TLR strategy by Isogawa et al. revealed that TLRs ligands except for TLR2 are able to induce antiviral cytokines (Interferon $\alpha / \beta$ ) at the site of HBV replication [16]. We therefore speculate that the increased serum TLR2 levels in our patients may correspond to higher expression of cellular TLR2 and consequently elevated TLR2 signaling leading to expression of proinflammatory cytokines that explain the chronicity of HBV infection that usually accompanies an increase in ALT.

In conclusion, our data show that the concentration of serum TLR2 was significantly higher in $\mathrm{HBeAg}$ negative patients with G1896A mutation which in turn was associated with higher serum ALT in this group. These results indicate the interaction of precore mutant strain of HBV and TLR2. Additional studies with longitudinal follow-up of subjects are required to determine the precise impact of TLR2 in HBeAg negative chronic hepatitis $\mathrm{B}$.

\section{Conflict of Interests}

The authors declare that they have no conflict of interests.

\section{Authors' Contribution}

All authors contributed both to the research and the discussion, and they have read and approved the final manuscript.

\section{Acknowledgments}

Authors of this article take this chance to appreciate all the patients which attended in this research program. This Study was supported by grants from the Digestive Disease Research Center, Tehran University of Medical Sciences.

\section{References}

[1] G. Montazeri, "Current treatment of chronic hepatitis B," Archives of Iranian Medicine, vol. 9, no. 1, pp. 1-10, 2006.

[2] P. Gerner, A. Hörning, S. Kathemann, K. Willuweit, and S. Wirth, "Growth abnormalities in children with chronic hepatitis B or C," Advances in Virology, vol. 2012, Article ID 670316, 5 pages, 2012.

[3] Y.-F. Liaw, M. R. Brunetto, and S. Hadziyannis, "The natural history of chronic HBV infection and geographical differences," Antiviral Therapy, vol. 15, supplement 3, pp. 25-33, 2010.

[4] H. Poustchi, A. Mohamadkhani, S. Bowden et al., "Clinical significance of precore and core promoter mutations in genotype D hepatitis B-related chronic liver disease," Journal of Viral Hepatitis, vol. 15, no. 10, pp. 753-760, 2008.

[5] S. M. Alavian, F. Fallahian, and K. B. Lankarani, "The changing epidemiology of viral hepatitis B in Iran," Journal of Gastrointestinal and Liver Diseases, vol. 16, no. 4, pp. 403-406, 2007.

[6] M. M. Mir-Nasseri, A. Mohammadkhani, H. Tavakkoli, E. Ansari, and H. Poustchi, "Incarceration is a major risk factor for 
blood-borne infection among intravenous drug users: incarceration and blood borne infection among intravenous drug users," Hepatitis Monthly, vol. 11, no. 1, pp. 19-22, 2011.

[7] A. Mohamadkhani, M. Sotoudeh, S. Bowden et al., "Downregulation of HLA class II molecules by G1896A pre-core mutation in chronic hepatitis B virus infection," Viral Immunology, vol. 22, no. 5, pp. 295-300, 2009.

[8] A. Mohamadkhani, A. Pourdadash, S. Tayebi et al., "The potential role of $\mathrm{APOBEC} 3 \mathrm{G}$ in limiting replication of hepatitis B virus," Arab Journal of Gastroenterology, vol. 13, no. 4, pp. 170$173,2012$.

[9] J.-Q. Lian, X.-Q. Wang, Y. Zhang, C.-X. Huang, and X.-F. Bai, "Correlation of circulating TLR2/4 expression with $\mathrm{CD}^{+} / 4^{+} / 8^{+}$ T cells and treg cells in HBV-related liver cirrhosis," Viral Immunology, vol. 22, no. 5, pp. 301-308, 2009.

[10] P. Carotenuto, A. Artsen, A. D. Osterhaus, and O. Pontesilli, "Reciprocal changes of naïve and effector/memory $\mathrm{CD}^{+} \mathrm{T}$ lymphocytes in chronic hepatitis B virus infection," Viral Immunology, vol. 24, no. 1, pp. 27-33, 2011.

[11] A. Mohamadkhani, F. Bastani, M. Sotoudeh et al., "Influence of B cells in liver fibrosis associated with hepatitis B virus harboring basal core promoter mutations," Journal of Medical Virology, vol. 84, no. 12, pp. 1889-1896, 2012.

[12] M. Schnare, G. M. Barton, A. C. Holt, K. Takeda, S. Akira, and R. Medzhitov, "Toll-like receptors control activation of adaptive immune responses," Nature Immunology, vol. 2, no. 10, pp. 947950, 2001.

[13] N. J. Gay and M. Gangloff, "Structure and function of toll receptors and their ligands," Annual Review of Biochemistry, vol. 76, pp. 141-165, 2007.

[14] E. E. Hamilton-Williams, A. Lang, D. Benke, G. M. Davey, K.H. Wiesmüller, and C. Kurts, "Cutting edge: TLR ligands are not sufficient to break cross-tolerance to self-antigens," Journal of Immunology, vol. 174, no. 3, pp. 1159-1163, 2005.

[15] D. R. Milich, M. K. Chen, J. L. Hughes, and J. E. Jones, “The secreted hepatitis B precore antigen can modulate the immune response to the nucleocapsid: a mechanism for persistence," Journal of Immunology, vol. 160, no. 4, pp. 2013-2021, 1998.

[16] M. Isogawa, M. D. Robek, Y. Furuichi, and F. V. Chisari, “Tolllike receptor signaling inhibits hepatitis $\mathrm{B}$ virus replication in vivo," Journal of Virology, vol. 79, no. 11, pp. 7269-7272, 2005

[17] K. Visvanathan, N. A. Skinner, A. J. V. Thompson et al., "Regulation of Toll-like receptor-2 expression in chronic hepatitis B by the precore protein," Hepatology, vol. 45, no. 1, pp. 102-110, 2007.

[18] M. K. Arababadi, A. A. Pourfathollah, A. Jafarzadeh, and G. Hassanshahi, "Serum levels of IL-10 and IL-17A in occult HBVinfected South-East Iranian patients," Hepatitis Monthly, vol. 10, no. 1, pp. 31-35, 2010.

[19] S. Tayebi and A. Mohamadkhani, "The TNF- $\alpha-308$ promoter gene polymorphism and chronic HBV infection," Hepatitis Research and Treatment, vol. 2012, Article ID 493219, 6 pages, 2012.

[20] E. LeBouder, J. E. Rey-Nores, N. K. Rushmere et al., "Soluble forms of Toll-like receptor (TLR) 2 capable of modulating TLR2 signaling are present in human plasma and breast milk," Journal of Immunology, vol. 171, no. 12, pp. 6680-6689, 2003.

[21] A.-C. Raby, E. Le Bouder, C. Colmont et al., "Soluble TLR2 reduces inflammation without compromising bacterial clearance by disrupting TLR2 triggering," Journal of Immunology, vol. 183, no. 1, pp. 506-517, 2009.
[22] K. Ishaka, A. Baptistab, L. Bianchic et al., "Histological grading and staging of chronic hepatitis," Journal of Hepatology, vol. 22, no. 6, pp. 696-699, 1995.

[23] R. B. Gan, M. J. Chu, L. P. Shen, S. W. Qian, and Z. P. Li, “The complete nucleotide sequence of the cloned DNA of hepatitis B virus subtype adr in pADR-1," Scientia Sinica B, vol. 30, no. 5, pp. 507-521, 1987.

[24] H. Kaur, A. Garg, and G. P. S. Raghava, "PEPstr: a de novo method for tertiary structure prediction of small bioactive peptides," Protein and Peptide Letters, vol. 14, no. 7, pp. 626-631, 2007.

[25] M. S. Jin, S. E. Kim, J. Y. Heo et al., "Crystal structure of the TLR1-TLR2 heterodimer induced by binding of a Tri-Acylated lipopeptide," Cell, vol. 130, no. 6, pp. 1071-1082, 2007.

[26] N. Andrusier, R. Nussinov, and H. J. Wolfson, "FireDock: fast interaction refinement in molecular docking," Proteins, vol. 69, no. 1, pp. 139-159, 2007.

[27] D. Schneidman-Duhovny, Y. Inbar, R. Nussinov, and H. J. Wolfson, "PatchDock and SymmDock: servers for rigid and symmetric docking," Nucleic Acids Research, vol. 33, supplement 2, pp. W363-W367, 2005.

[28] C.-M. Chu, C.-T. Yeh, C.-S. Lee, I.-S. Sheen, and Y.-F. Liaw, "Precore stop mutant in HBeAg-positive patients with chronic hepatitis B: clinical characteristics and correlation with the course of HBeAg-to-anti-HBe seroconversion," Journal of Clinical Microbiology, vol. 40, no. 1, pp. 16-21, 2002.

[29] S. A. Taghavi, M. Tabibi, A. Eshraghian, H. Keyvani, and H. Eshraghian, "Prevalence and clinical significance of hepatitis B basal core promoter and precore gene mutations in southern iranian patients," Hepatitis Monthly, vol. 10, no. 4, pp. 294-297, 2010.

[30] H. P. Dienes, G. Gerken, B. Goergen, K. Heermann, W. Gerlich, and K. H. M. zum Buschenfelde, "Analysis of the precore DNA sequence and detection of precore antigen in liver specimens from patients with anti-hepatitis B e-positive chronic hepatitis," Hepatology, vol. 21, no. 1, pp. 1-7, 1995.

[31] C.-M. Chu and Y.-F. Liaw, "Predictive factors for reactivation of hepatitis B following hepatitis B e antigen seroconversion in chronic hepatitis B," Gastroenterology, vol. 133, no. 5, pp. 14581465, 2007.

[32] C. P. Desmond, S. Gaudieri, I. R. James et al., "Viral adaptation to host immune responses occurs in chronic hepatitis B virus (HBV)infection, and adaptation is greatest in HBV e antigennegative disease," Journal of Virology, vol. 86, no. 2, pp. 1181-1192, 2012.

[33] R. Romieu-Mourez, M. François, M.-N. Boivin, M. Bouchentouf, D. E. Spaner, and J. Galipeau, "Cytokine modulation of TLR expression and activation in mesenchymal stromal cells leads to a proinflammatory phenotype," Journal of Immunology, vol. 182, no. 12, pp. 7963-7973, 2009.

[34] T. Matsumura, T. Degawa, T. Takii et al., "TRAF6-NF- $\kappa$ B pathway is essential for interleukin-1-induced TLR2 expression and its functional response to TLR2 ligand in murine hepatocytes," Immunology, vol. 109, no. 1, pp. 127-136, 2003. 

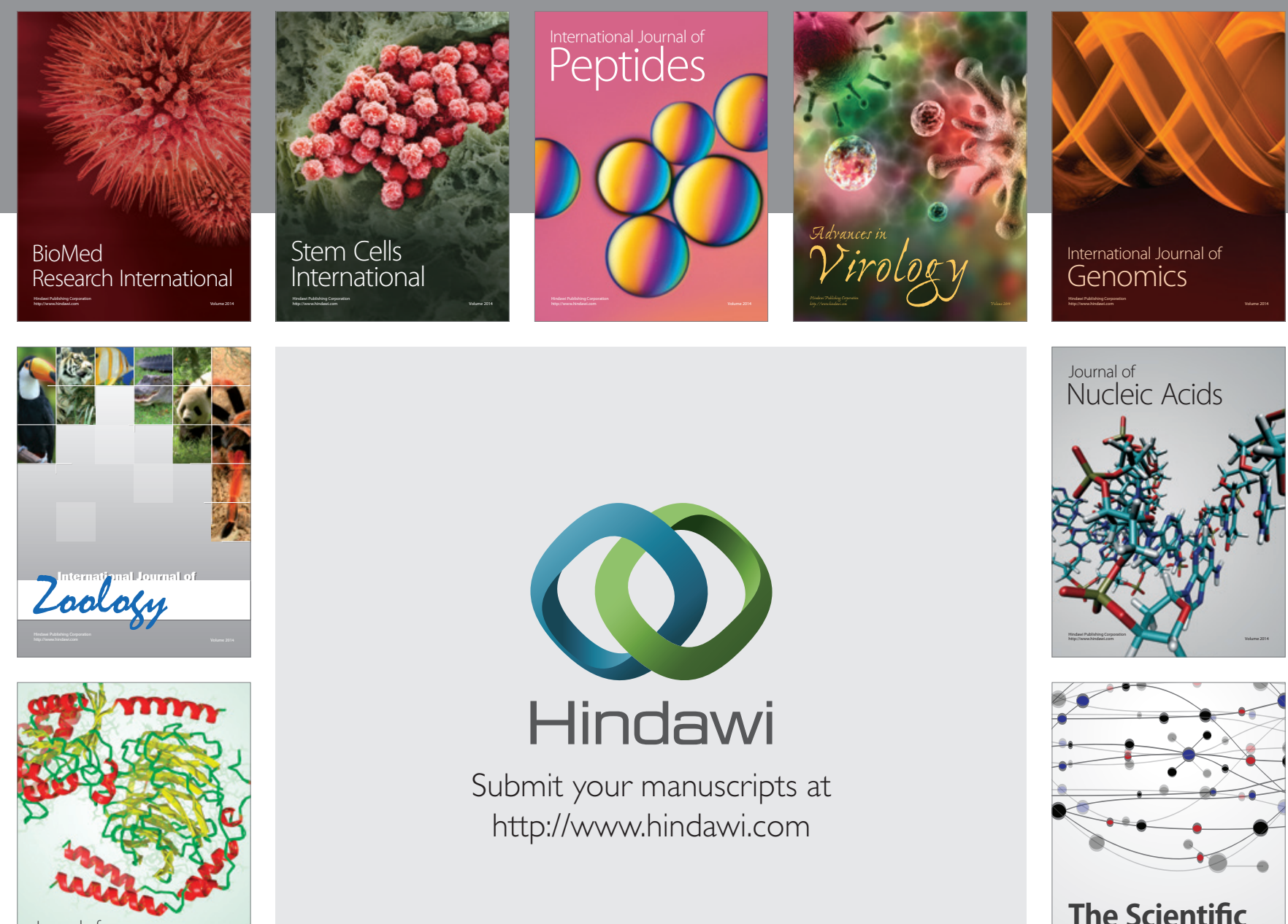

Submit your manuscripts at

http://www.hindawi.com

Journal of
Signal Transduction
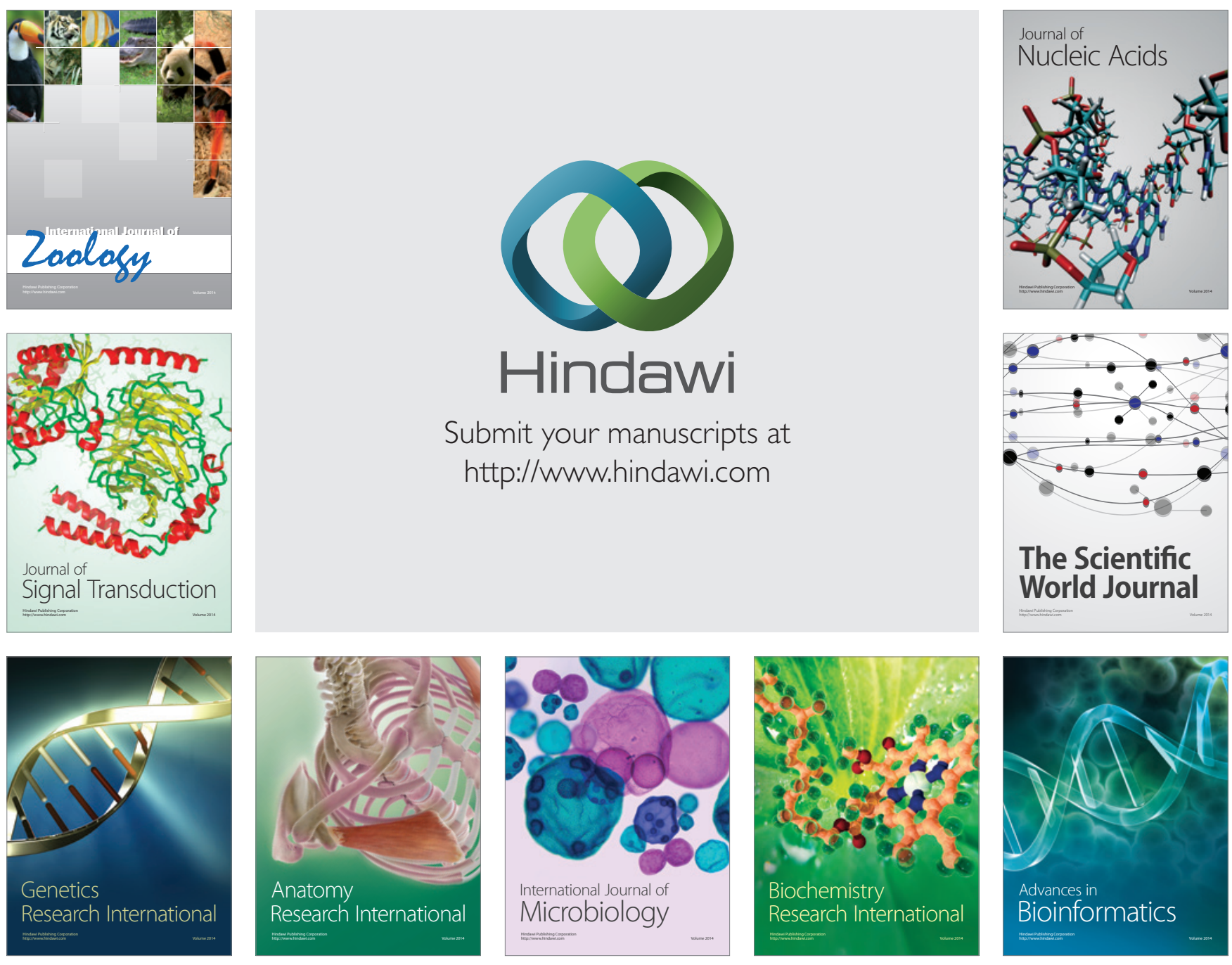

The Scientific World Journal
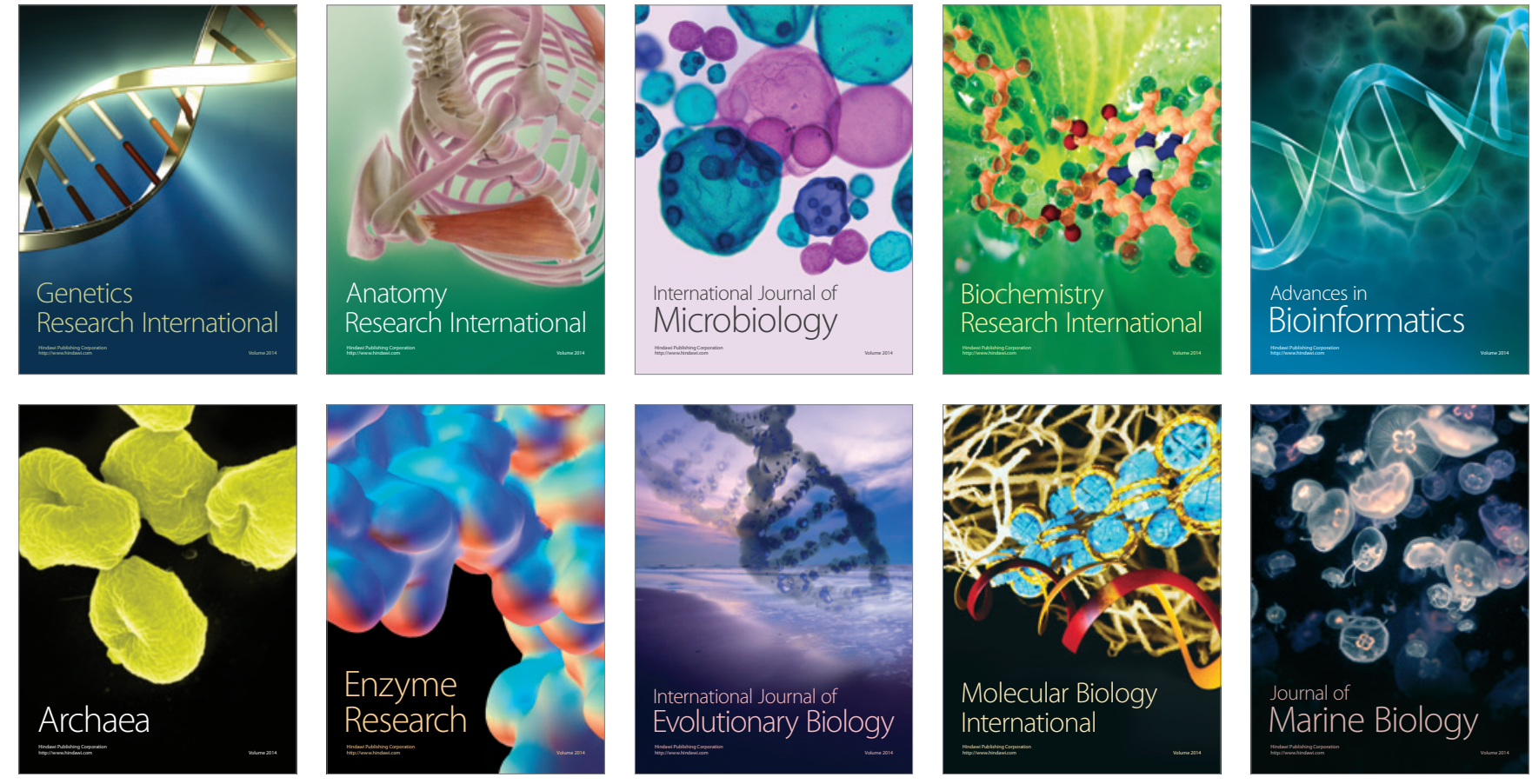